\title{
The perception of Italian pregnant women and new mothers about their psychological wellbeing, lifestyle, delivery, and neonatal management experience during the COVID-19 pandemic lockdown: a web- based survey
}

Viviana Stampini ${ }^{*}$, Alice Monzani ${ }^{2}$, Silvia Caristia ${ }^{4}$, Gianluigi Ferrante ${ }^{5}$, Martina Gerbino ${ }^{1}$, Alberto De Pedrini ${ }^{3}$, Roberta Amadori ${ }^{3}$, Ivana Rabbone ${ }^{2}$ and Daniela Surico ${ }^{1}$

\begin{abstract}
Background: In response to the COVID-19 pandemic, drastic measures for social distancing have been introduced also in Italy, likely with a substantial impact in delicate conditions like pregnancy and puerperium. The study aimed to investigate the changes in lifestyle, access to health services, and mental wellbeing during the first Italian lockdown in a sample of Italian pregnant women and new mothers.

Methods: We carried out a web-based survey to evaluate how pregnant women and new mothers were coping with the lockdown. We collected data about healthy habits (physical exercise and dietary habits), access to health services (care access, delivery and obstetric care, neonatal care, and breastfeeding), and mental wellbeing (psychological well-being and emotive support). Descriptive analysis was performed for both groups of participants, whereas a Poisson analysis was used to measure the association between some structural variables (age, education, socio-economic data, partner support, contact, free time, previous children, and pregnancy trimester) and anxiety or depression, difficulties in healthy eating and reduction in physical activity after lockdown started. Chi2 and Adjusted Prevalence Ratios were estimated only for pregnant women.

Results: We included 739 respondents (response rate $85.8 \%$ ), 600 were pregnant (81.2\%), and $139(18.8 \%$ ) had delivered during lockdown (new mothers). We found a high score for anxiety and depression in $62.8 \%$ of pregnant women and $61.9 \%$ of new mothers. During the lockdown, $61.8 \%$ of pregnant women reduced their physical exercise, and $44.3 \%$ reported eating in a healthier way. $94.0 \%$ of new mothers reported to have breastfed their babies during the hospital stay. Regarding the perceived impact of restrictive measures on breastfeeding, no impact was reported by $56.1 \%$ of new mothers, whereas a negative one by $36.7 \%$.
\end{abstract}

\footnotetext{
* Correspondence: Viviana.stampini@med.uniupo.it

'Obstetrics and Gynecology Unit, Department of Translational Medicine,

University of Eastern Piedmont, Via Solaroli 17, 28100 Novara, Italy

Full list of author information is available at the end of the article
}

C C The Author(s). 2021 Open Access This article is licensed under a Creative Commons Attribution 4.0 International License, which permits use, sharing, adaptation, distribution and reproduction in any medium or format, as long as you give appropriate credit to the original author(s) and the source, provide a link to the Creative Commons licence, and indicate if changes were made. The images or other third party material in this article are included in the article's Creative Commons licence, unless indicated otherwise in a credit line to the material. If material is not included in the article's Creative Commons licence and your intended use is not permitted by statutory regulation or exceeds the permitted use, you will need to obtain permission directly from the copyright holder. To view a copy of this licence, visit http://creativecommons.org/licenses/by/4.0/. The Creative Commons Public Domain Dedication waiver (http://creativecommons.org/publicdomain/zero/1.0/) applies to the data made available in this article, unless otherwise stated in a credit line to the data. 
Conclusions: The high prevalence of anxiety and depressive symptoms in pregnant women and new mothers should be a public health issue. Clinicians might also recommend and encourage "home" physical exercise. On the other hand, about half of the sample improved their approach towards healthy eating and a very high breastfeeding rate was reported soon after birth: these data are an interesting starting point to develop new strategies for public health.

Keywords: COVID-19, Lockdown, Pregnancy, New mothers, Breastfeeding, Healthy eating, Physical exercise.

\section{Background}

Since the severe acute respiratory syndrome SARS-CoV2 started to spread across several countries, the World Health Organization declared that the outbreak was a public health emergency of international concern (http://www.euro.who.int/en/health-topics/healthemergencies/coronavirus-covid-19/news/news/2020/3/ who-announces-covid-19-outbreak-a-pandemic). Based on the Chinese experience [1], starting from March 9th, 2020, drastic measures have been introduced also in Italy: citizens were banned from leaving their homes unless for urgent needs. As a consequence, a sudden and radical change in habits and lifestyles of the whole population, a minimization of socialization, and changes in both interpersonal relationships and organization of work occurred. Hospital activity was radically changed: many departments were closed to create COVID-19 dedicated hospital wards, the rest of the clinical activity was downsized, and contacts with patients were reduced to a minimum. Measures such as redefinition of care priorities and several restrictions would presumably lead to changes in the health of the population in the coming months or years.

There are still many unanswered questions regarding the effects of lockdown measures on pregnant women $[2,3]$. Healthcare workers are facing an important challenge in terms of reshaping obstetric care to avoid unnecessary exposure to patients, without impairing the required attention. Although obstetric units have not diminished their working activity, there have been changes in territorial and hospital care. The pre-birth courses have been officially stopped; some screening tests have been performed much less frequently, due to reduced patient access or to difficulties in providing services. Family members and partner presence during important moments, such as ultrasound scans and hospitalization, has been reduced for safety reasons.

Most of the pregnant women and new mothers were forced into homebound isolation, often with other children to look after, without any domestic help [4]. On the other hand, some women may have welcomed the chance of working from home and, in some cases, they may have benefited from a greater presence of their partner.
It can be assumed that these changes influenced pregnancy, puerperium, and newborn management with consequences worthy of obstetrics consideration [3]. While published studies on the possible effects of COVID-19 disease in pregnant women and infants are increasing [5], there are only a few studies $[6,7,8]$ dealing with the psychological effects of the pandemic on pregnant women and new mothers.

The purpose of this study was to describe the lifestyle, access to health services, and mental wellbeing of Italian pregnant women and new mothers during the first phase of lockdown (April - May, 2020). In addition, we aimed to assess the association between socio-demographic characteristics and living/housing conditions with (i) anxiety and depression, (ii) healthy eating habits, and (iii) physical exercise.

\section{Methods \\ Study Design, setting and participants}

A survey investigating lifestyle, access to health services, and mental wellbeing of Italian pregnant women and new mothers was conducted from April 9th, 2020 to May 3rd, 2020. It was a cross-sectional study based on an anonymous web survey to collect information through an online electronic questionnaire, accessible from smartphones, tablets, and personal computers.

\section{Survey methodology}

To recruit respondents, a non-probabilistic snowball sampling approach was used, disseminating the weblink of the online survey through social media (Facebook and Instagram pages addressing new mothers and pregnant women) and newspaper sections on women issues. Individuals were directed via an electronic link to an online survey platform (Google Forms). Duplicate entries were avoided by asking people to provide their e-mail address at the end of the survey; duplicate entries having the same e-mail address were eliminated before the analysis and the first entry was kept. The survey was not displayed a second time once the responder had filled it in, but the link to pass it on to others was available. Responses to the survey were automatically captured into a database. All responses included a non-response option, 
such as "not applicable" or "rather not say" in order to avoid missing data.

\section{Ethical considerations}

The survey was preceded by a fact sheet including information on what the research was about, the reason the research was being conducted, how the data would be used, how the privacy of the data would be maintained, and information in case the respondents changed their mind during the survey, along with contact details for further information. Afterward, consent to participate was obtained at the very beginning of the survey, as participants were required to check a box to indicate their consent before accessing the questionnaire. The participation in the survey was voluntary and anonymous. Approval was obtained from the local Ethical Committee (Comitato Etico Interaziendale Novara CE 71/20), which conformed to the principles embodied in the Declaration of Helsinki.

\section{Variables and data sources}

Expected outcomes of the baseline analysis included different topics that could be influenced by the lockdown measures and were categorized in different analysis domains, related to pregnancy and puerperium.

For the pregnancy group, the analyzed domains were 1- psychological well-being and support; 2- physical exercise; 3- dietary habits; 4- access to care. Regarding puerperium, the analyzed domains were 5- psychological well-being and support; 6- delivery and obstetric care; 7neonatal care and breastfeeding.

Due to the lack of validated questionnaires about this topic, the authors reviewed previous and current surveys [9] on the impact of the pandemic and included additional questions related to pregnancy and birth [10, 11, 12], developing an ad hoc questionnaire (Supplementary material). To investigate the psychological impact, we used the Patient Health Questionnaire for Depression and Anxiety (the PHQ-4)[13]. PHQ-4 is a four-item scale with a total score ranging from 0 to 12 that aims to identify the following categories of psychological distress: none (0-2), mild (3-5), moderate (6-8), and severe (9-12). The questionnaire was tested in a sample of voluntary pregnant women and new mothers with different characteristics (age, education, parity) who reviewed the questionnaire individually and provided verbal feedback, and it was also submitted to a panel of experts (psychologists, midwives, epidemiologists), for content validity and construct coherence. Completion time was about $15 \mathrm{~min}$. The survey was performed according to the Checklist for Reporting Results of Internet E-Surveys (CHERRIES) [11].

The survey consisted of a common part including sociodemographic and psychological questions, addressing both pregnant women and new mothers, followed by a specific part dedicated either to pregnant women or women who gave birth during the lockdown, each divided into subsections of questions, addressing different analysis domains. The completion of only some items of the survey was mandatory for all who visited the site. All submitted questionnaires were complete for the mandatory items. Items in the survey were not randomized or alternated for different survey respondents. Certain questions only displayed based on responses to other questions.

\section{Statistical analysis}

A descriptive analysis was carried out to report the main socio-demographic characteristics and the living and housing conditions of the respondents by frequency distribution, separately for pregnant women and new mothers. Among pregnant women, psychological aspects, living habits during lockdown, and access to care were described, and among new mothers, the experience related to childbirth during lockdown was reported.

Crude associations between socio-demographic characteristics, living and housing conditions, and (i) anxiety and depression, (ii) healthy eating habits, and (iii) physical exercise were assessed by the chi2 test, setting the level of significance at 0.05 . Poisson regression models were used to assess the same associations, adjusted for the variables included in the analysis (age, education, economically satisfied, satisfied with their home, partner support, contact with other people, availability of free time, having other children at home, and trimester of pregnancy). Adjusted Prevalence Ratios (Adj PR) were calculated along with $95 \%$ confidence intervals.

Response rates for both groups were very high (see below), so we excluded from the analysis missing data (following Complete Case Analysis) supposing a random mechanism generating missing data (Missing Completely At Random).

Statistical analysis was performed using Stata Statistical Software: Release 15. StataCorp LLC.

\section{Results}

The first page of the survey was visited by 861 women (Fig. 1). Eight (0.9\%) women did not give their consent to participate, $110(12.8 \%)$ were excluded because either not pregnant or not having delivered during lockdown, and $3(0.5 \%)$ because not living in Italy during the interview. Thus, we included 739 respondents from 18 different Italian regions, who completed the questionnaire (completion rate: $96 \%$ ). Overall, 600 respondents were pregnant $(81.2 \%)$ and $139(18.8 \%)$ had delivered in the lockdown period. 


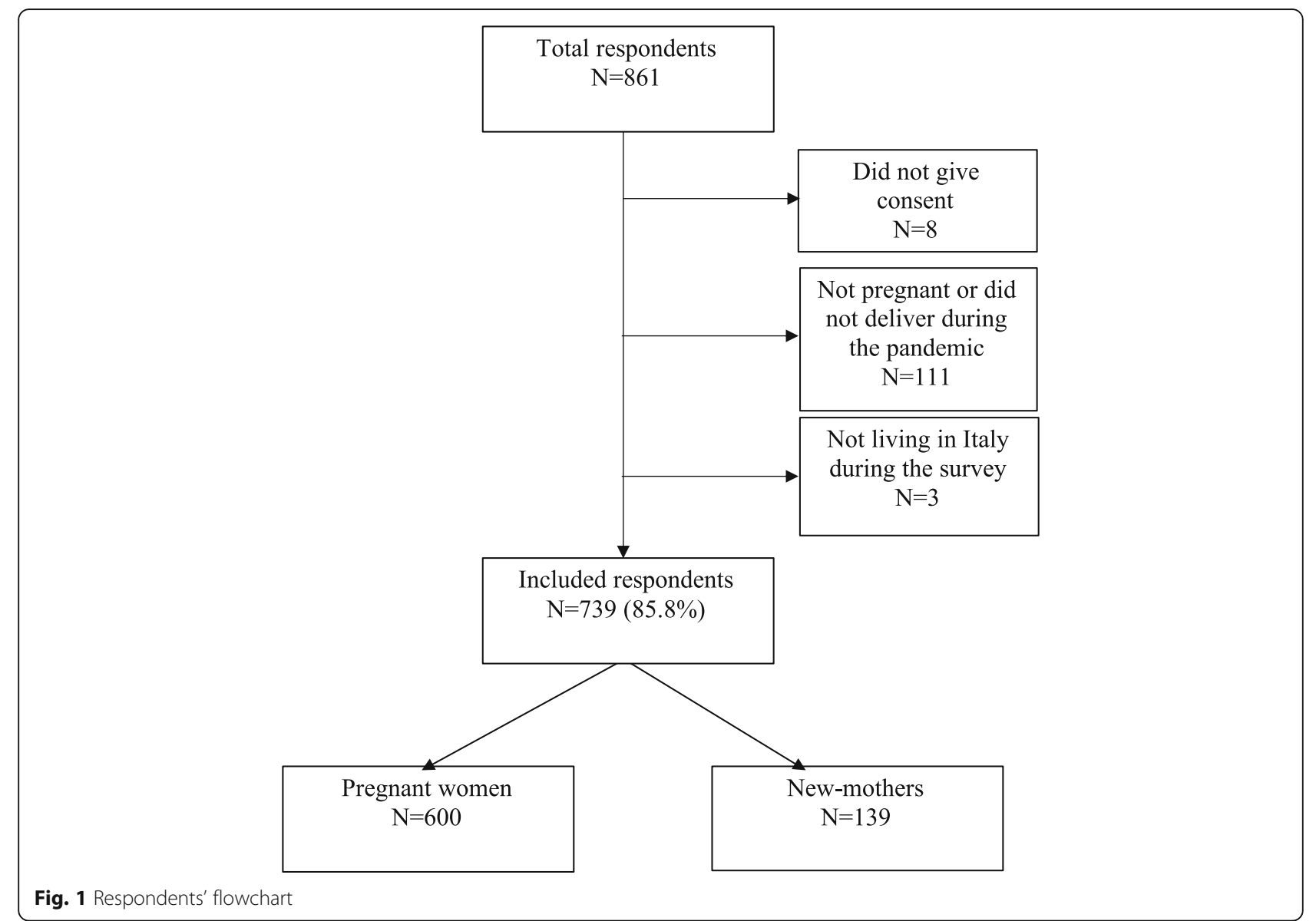

Sociodemographic, living, housing, and psychological characteristics of pregnant women and new mothers

Data are reported in Table 1 . The overall response rate for these items was $>99 \%$. Pregnant women were aged 18 to 48 years with a mean age of $33.1 \pm 4.3,61.6 \%$ of the sample had at least a bachelor degree, $47.7 \%$ of the sample reported being economically satisfied (highly sufficient to their needs). Most of them (81\%) were from Northern Italy. The PHQ-4 score ranged from moderate to severe (scores from 6 to 12 ) for $62.8 \%$ of women. Finally, $83.2 \%$ of women recognized their partner as the person who was supporting them during the lockdown.

New mothers were aged 25 to 41 years with a mean of $33.6 \pm 4.0,73.4 \%$ had at least a bachelor degree, and $47.4 \%$ of the sample was economically satisfied. Similarly to pregnant women, for $61.9 \%$ of new mothers the PHQ4 score ranged from moderate to severe and the partner was the most cited supporting person $(87.1 \%)$. Almost the overall sample $(89.9 \%)$ was living in Northern Italy.

\section{Changes in the lifestyle of pregnant women during lockdown}

Table 2 describes some aspects of pregnant women's lifestyle and how the social distancing measures changed their habits (dietary habits, physical exercise, and access to care). The overall response rate for these items was $>96 \%$. Many women $(79.0 \%)$ declared that the greater presence of their partner positively influenced pregnancy. On the other hand, $71.7 \%$ of them were afraid of delivering alone and $44.5 \%$ declared they were living a stressful situation. Regarding physical exercise, the reported minutes of weekly physical activity were significantly decreased during lockdown (before: $142.2 \mathrm{~min}, 95 \%$ CI 135.0-149.4, vs. after: $105.1 \mathrm{~min}, 95 \%$ CI 96.7-113.4, with a mean reduction of $38.5 \mathrm{~min} \pm 90.3$ during the lockdown, $p<0.05$ ). Specifically, $61.8 \%$ of women reduced their physical exercise during the lockdown.

Concerning dietary habits, according to $44.3 \%$ of women, social restrictions gave them the chance to eat more healthily.

Regarding access to health care services, only $24.9 \%$ of women in our sample was attending an online pre-birth course and $12 \%$ of them avoided access to an ob-gyn emergency department for fear of contagion, preferring phone contact with a gynecologist or a midwife. Finally, $26.5 \%$ of our sample skipped some planned check-up and $18.8 \%$ skipped planned tests or vaccinations. 
Table 1 Socio-demographic characteristics, housing and living conditions in pregnant women and new mothers

\begin{tabular}{|c|c|c|c|c|c|c|}
\hline & \multirow[t]{2}{*}{ Parameter } & \multirow[t]{2}{*}{ Category } & \multicolumn{2}{|c|}{$\begin{array}{l}\text { Pregnant } \\
\text { women } \\
(N=600)\end{array}$} & \multicolumn{2}{|c|}{$\begin{array}{l}\text { New } \\
\text { mothers } \\
(N=139)\end{array}$} \\
\hline & & & $\mathbf{n}$ & $\%$ & $\mathbf{n}$ & $\%$ \\
\hline \multirow[t]{13}{*}{ Socio-demographic characteristics } & Age & From 18 to 34 & 379 & $63.2 \%$ & 82 & $59.0 \%$ \\
\hline & & From 35 to 48 & 221 & $36.8 \%$ & 57 & $41.0 \%$ \\
\hline & Education & Less than Bachelor & 230 & $\begin{array}{l}38.4 \% \\
a\end{array}$ & 37 & $26.6 \%$ \\
\hline & & More than bachelor & 369 & $\begin{array}{l}61.6 \% \\
a\end{array}$ & 102 & $73.4 \%$ \\
\hline & Area of residence & North & 486 & $80.6 \%$ & 125 & $89.9 \%$ \\
\hline & & Centre & 65 & $10.8 \%$ & 12 & $8.6 \%$ \\
\hline & & South & 49 & $8.2 \%$ & 2 & $1.4 \%$ \\
\hline & City or village & City or suburbs of a city & 282 & $\begin{array}{l}47.2 \% \\
a\end{array}$ & 60 & $43.2 \%$ \\
\hline & & Village & 316 & $52.8 \%$ & 79 & $56.8 \%$ \\
\hline & Economic resources & Not adeguate & 312 & $52.0 \%$ & 72 & $\begin{array}{l}52.6 \% \\
a\end{array}$ \\
\hline & & Very adeguate & 285 & $\begin{array}{l}47.7 \% \\
a\end{array}$ & 65 & $\begin{array}{l}47.4 \% \\
a\end{array}$ \\
\hline & Working conditions & In-work & 454 & $75.8 \%$ & 108 & ${ }_{a}^{78.3 \%}$ \\
\hline & & Not in-work & 145 & $24.2 \%$ & 30 & $21.7 \%$ \\
\hline \multirow[t]{8}{*}{ Housing } & House size & Less than $100 \mathrm{sm}$ & 387 & $64.5 \%$ & 94 & $67.6 \%$ \\
\hline & & More than $100 \mathrm{sm}$ & 213 & $35.5 \%$ & 45 & $32.4 \%$ \\
\hline & Satisfied with the house & no & 232 & $38.7 \%$ & 54 & $38.8 \%$ \\
\hline & & yes & 368 & $61.3 \%$ & 85 & $61.1 \%$ \\
\hline & Presence of a garden & Yes & 253 & $42.2 \%$ & 53 & $38.4 \%$ \\
\hline & & No & 347 & $57.8 \%$ & 85 & $61.6 \%$ \\
\hline & Adequacy of electronic devices & Not adeguate & 136 & $22.7 \%$ & 41 & $29.5 \%$ \\
\hline & & Very adeguate & 464 & $77.3 \%$ & 98 & $70.5 \%$ \\
\hline \multirow[t]{11}{*}{ Social-living } & Presence of partner & Always at home & 311 & $51.8 \%$ & 70 & $50.4 \%$ \\
\hline & & $\begin{array}{l}\text { At home but still going to } \\
\text { work }\end{array}$ & 275 & $45.8 \%$ & 65 & $46.8 \%$ \\
\hline & & Not co-living & 14 & $2.3 \%$ & 4 & $2.9 \%$ \\
\hline & Other children at home & No & 406 & $67.7 \%$ & 99 & $71.2 \%$ \\
\hline & & Yes & 194 & $32.3 \%$ & 40 & $28.8 \%$ \\
\hline & Someone else co-living & No & 556 & $92.7 \%$ & 123 & $88.5 \%$ \\
\hline & & Yes & 44 & $7.3 \%$ & 16 & $11.5 \%$ \\
\hline & Contacts with other people & No & 376 & $62.7 \%$ & 71 & $\begin{array}{l}51.4 \% \\
a\end{array}$ \\
\hline & & Yes & 224 & $37.3 \%$ & 67 & $\begin{array}{l}48.6 \% \\
a\end{array}$ \\
\hline & Adherence to the restrictions & From little to average & 12 & $2.00 \%$ & 1 & $0.7 \%$ \\
\hline & & High & 588 & $98.0 \%$ & 138 & $99.3 \%$ \\
\hline \multirow{3}{*}{$\begin{array}{l}\text { Psychological wellbeing and } \\
\text { support }\end{array}$} & Depression and anxiety score (PHQ-4 score) ${ }^{b}$ & Normal to mild & 223 & $37.2 \%$ & 53 & $38.1 \%$ \\
\hline & & Moderate to severe & 378 & $62.8 \%$ & 86 & $61.9 \%$ \\
\hline & People supporting (more than one choice & Partner & 499 & $83.2 \%$ & 121 & $87.1 \%$ \\
\hline
\end{tabular}


Table 1 Socio-demographic characteristics, housing and living conditions in pregnant women and new mothers (Continued)

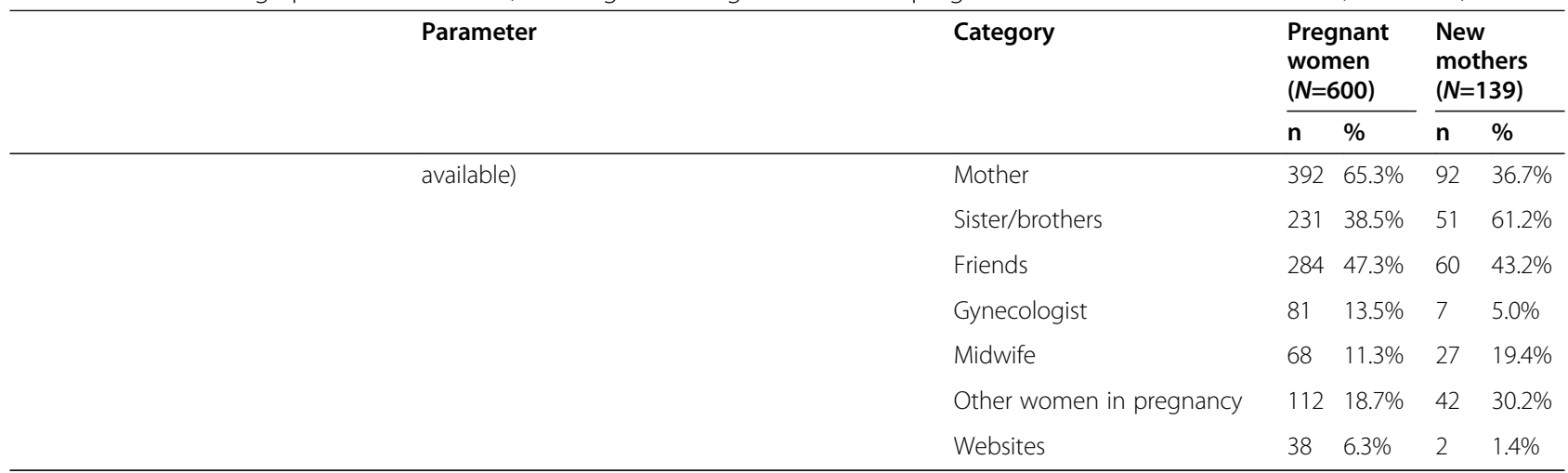

a Presence of missing data for these variables. Percentages were calculated on total of respondents: PREGNANT WOMEN Education ( $N=599)$, City or village $(N=$ 598), Economic resources $(N=597)$, Working conditions $(N=599)$. NEW MOTHERS Economic resources $(N=137)$, Working conditions $(N=138)$; ${ }^{b}$ PHQ-4 is a four items scale with a total score ranging from 0 to 12 and aims to identify the following categories of psychological distress: none (0-2), mild (3-5), moderate (6-8), and severe (9-12)

\section{The experience of delivering during lockdown for new mothers}

Table 3 describes the experience of delivery and baby management during lockdown. The overall response rate for these items was $>99 \%$. The mean gestational age at the time of delivery was $39.4 \pm 1.3$ weeks (range 36-42 weeks). $92.4 \%$ of the partners had the possibility to be present during labor. $75.3 \%$ of women declared they were afraid of giving birth during the COVID-19 pandemic. They reported that the delivery experience was as they expected in $50.8 \%$ of cases, better than expected in $36.2 \%$.

Overall, the restrictive measures had a negative impact on baby management for $61.1 \%$ of the new mothers, and no impact for $28.1 \%$. Most of the respondents reported to have breastfed their babies during the hospital stay $(94.2 \%)$ and about two-thirds of them started breastfeeding within the first two hours after delivery (64.7\%). During the hospital stay, $70.5 \%$ of the babies were exclusively breastfed, $27.3 \%$ received formula feeding, and $2.2 \%$ received human donor milk. The majority of the new mothers declared to have continued to breastfeed their babies when discharged at home (95.0\%), and most of them (91.7\%) stated they were still breastfeeding the babies at the time of the survey, reporting exclusive breastfeeding in $85.0 \%$ of cases and mixed with formula feeding in $5.8 \%$.

No impact of restrictive measures on breastfeeding was reported by $56.1 \%$ of the new mothers, a negative impact by $36.7 \%$, and a positive one by $7.2 \%$. After hospital discharge, the respondents reported having received no support for breastfeeding in $53.2 \%$ of cases, whereas $55.4 \%$ of women who received support claimed that this came from a midwife and $41.5 \%$ from their partner. Only a few of the respondents (6.1\%) reported having had support from a pediatrician for breastfeeding during the first period after discharge. In our sample, only 3 women $(2.2 \%)$ reported to have had confirmed SARSCoV-2 infection at the time of delivery: all of them were separated from their newborns maintaining the possibility to feed them with expressed breast milk. Regarding the rest of the respondents, it was not known if they were not tested or tested negative, because it was not inquired in the survey.

\section{Adjusted analysis for pregnant women}

Table 4 shows $X^{2}$ and prevalence across independent variables and three crucial outcomes in the pregnant women group: PH4 scores from moderate to severe, difficulties in healthy eating and reduction in physical exercise.

Poisson analysis showed that women with partner support during pregnancy and satisfied with economic and house resources were less likely to report higher anxiety and depression scores (respectively - $23 \%,-27 \%$, and $25 \%$ ) compared to women without partner support and not satisfied with economic and house resources.

While for most women restrictions gave them the chance to eat more healthily, $20.2 \%$ of women reported difficulties in healthy eating. In particular, women with partner support declared less difficulty in healthy eating (-31\%). Likewise, higher educational attainment was also associated with less difficulty in healthy eating (PR 0.70, $95 \%$ CI 0.53-0.86).

Lastly, during lockdown there was a significant reduction in physical activity, but this data is transversal to all respondents and there are no significant differences between groups, except for the trimester of pregnancy: women in the second and third trimesters were less likely to have reduced levels of physical activity during lockdown ( -36 and $-34 \%$, respectively) in comparison to women in the first trimester. 
Table 2 Changes in lifestyle during the lockdown among pregnant women

\begin{tabular}{|c|c|c|c|c|}
\hline & Parameter & Category & $N=600$ & $\%$ \\
\hline \multirow{10}{*}{$\begin{array}{l}\text { Other psychological } \\
\text { aspects }\end{array}$} & \multirow[t]{3}{*}{ Influence of partner at home $(N=586)^{a}$} & Positive influence & 444 & $79.0 \%$ \\
\hline & & Negative influence & 11 & $2.0 \%$ \\
\hline & & No influence & 107 & $19.0 \%$ \\
\hline & \multirow[t]{3}{*}{ Influence of children at home $(N=194)^{a}$} & Positive influence & 51 & $26.7 \%$ \\
\hline & & Negative influence & 70 & $36.7 \%$ \\
\hline & & No influence & 70 & $36.7 \%$ \\
\hline & \multirow[t]{2}{*}{ Fear of delivering alone } & Low & 170 & $28.3 \%$ \\
\hline & & High & 430 & $71.7 \%$ \\
\hline & \multirow[t]{2}{*}{ Stress about the future } & Low to average & 333 & $55.5 \%$ \\
\hline & & High & 267 & $44.5 \%$ \\
\hline \multirow[t]{11}{*}{ Physical exercise } & \multirow[t]{2}{*}{ Weekly exercise before the restrictions $(N=460)$} & More than $2 \mathrm{~h}$ & 268 & $58.3 \%$ \\
\hline & & Less than $2 \mathrm{~h}$ & 192 & $41.7 \%$ \\
\hline & \multirow[t]{2}{*}{ Weekly exercise after the restrictions $(N=359)$} & More than $2 \mathrm{~h}$ & 139 & $38.8 \%$ \\
\hline & & Less than $2 \mathrm{~h}$ & 220 & $61.3 \%$ \\
\hline & \multirow{3}{*}{$\begin{array}{l}\text { Changes pre vs. post lock-down of weekly minutes of physical exercise } \\
(N=503)\end{array}$} & As before & 88 & $17.5 \%$ \\
\hline & & More than before & 104 & $20.7 \%$ \\
\hline & & Less than before & 311 & $61.8 \%$ \\
\hline & \multirow[t]{2}{*}{ Restrictions gave you the chance to exercise more } & Yes & 86 & $14.3 \%$ \\
\hline & & No & 514 & $85.7 \%$ \\
\hline & \multirow[t]{2}{*}{ Not walking outside: influence on your wellbeing ${ }^{\text {a }}$} & Low & 115 & $80.8 \%$ \\
\hline & & High & 484 & $19.2 \%$ \\
\hline \multirow[t]{2}{*}{ Dietary habits } & \multirow[t]{2}{*}{ Restrictions gave you the chance to eat more healthily ${ }^{a}$} & Yes & 266 & $44.3 \%$ \\
\hline & & No & 334 & $55.7 \%$ \\
\hline \multirow[t]{13}{*}{ Access to care } & \multirow[t]{3}{*}{ Participation in online pre-birth course ${ }^{a}$} & Currently participating & 149 & $24.9 \%$ \\
\hline & & About to start & 10 & $1.7 \%$ \\
\hline & & Not participating & 439 & $73.4 \%$ \\
\hline & \multirow[t]{2}{*}{ Access to emergency room } & Gave up to go to ER & 72 & $12.0 \%$ \\
\hline & & No events & 528 & $88.0 \%$ \\
\hline & \multirow[t]{4}{*}{ How did you solve the problem $(N=72)$} & $\begin{array}{l}\text { Phone call with } \\
\text { Gynecologist }\end{array}$ & 56 & $77.8 \%$ \\
\hline & & Phone call with midwife & 24 & $33.3 \%$ \\
\hline & & $\begin{array}{l}\text { Visit to private } \\
\text { Gynecologist }\end{array}$ & 35 & $48.6 \%$ \\
\hline & & Did not resolve & 5 & $6.9 \%$ \\
\hline & \multirow[t]{2}{*}{ did you skip any planned check up? } & Yes & 159 & $26.5 \%$ \\
\hline & & No & 441 & $73.5 \%$ \\
\hline & \multirow[t]{2}{*}{ did you skip any planned test or vaccination? ${ }^{a}$} & Yes & 112 & $18.8 \%$ \\
\hline & & No & 483 & $81.2 \%$ \\
\hline
\end{tabular}

a Presence of missing data for these variables. Percentages were calculated on total of respondents: Influence of partner at home $(N=562)$, Not walking influences on your wellbeing $(N=599)$, Participation in online pre-birth course $(N=598)$, Have you skipped any planned test or vaccination $(N=595)$

\section{Discussion}

This study describes how pregnant women managed to cope with lockdown in Italy. We found a high score for anxiety and depression, although it cannot be compared to the same score on the same population before the pandemic. Our survey also suggests that lockdown made it more difficult for pregnant women to exercise for 150 min per week in accordance with the ACOG guidelines [14], and we can assume that a reduction in physical exercise will affect the quality of life of pregnant 
Table 3 The experience of delivering during the lockdown among new mothers

\begin{tabular}{|c|c|c|c|c|}
\hline & Parameter & Category & $N=139$ & $\%$ \\
\hline \multirow{10}{*}{$\begin{array}{l}\text { Delivery and obstetrics } \\
\text { care }\end{array}$} & \multirow[t]{3}{*}{ Delivery mode } & Vaginal Eutocic & 96 & $69.1 \%$ \\
\hline & & Vaginal dystonic & 22 & $15.8 \%$ \\
\hline & & Caesarean section & 21 & $15.1 \%$ \\
\hline & \multirow[t]{2}{*}{ Presence of partner during delivery $(N=118)^{b}$} & Yes & 109 & $92.4 \%$ \\
\hline & & No & 9 & $15.8 \%$ \\
\hline & \multirow[t]{2}{*}{ Worried about receiving lower quality assistance because of the pandemic ${ }^{a}$} & Yes & 60 & $44.1 \%$ \\
\hline & & No & 76 & $55.9 \%$ \\
\hline & \multirow[t]{3}{*}{ Reality versus expectations for you ${ }^{a}$} & As expected & 67 & $50.7 \%$ \\
\hline & & Better & 50 & $36.2 \%$ \\
\hline & & Worst & 18 & $13.0 \%$ \\
\hline \multirow{27}{*}{$\begin{array}{l}\text { Neonatal care and } \\
\text { breastfeeding }\end{array}$} & \multirow[t]{2}{*}{ Required neonatal intensive care } & Yes & 15 & $10.8 \%$ \\
\hline & & No & 124 & $89.2 \%$ \\
\hline & \multirow[t]{2}{*}{ Worried about receiving lower quality neonatal assistance ${ }^{\text {a }}$} & Yes & 36 & $26.0 \%$ \\
\hline & & No & 102 & $74.0 \%$ \\
\hline & \multirow[t]{3}{*}{ Reality versus expectations for your baby } & As expected & 83 & $59.7 \%$ \\
\hline & & Better & 42 & $30.2 \%$ \\
\hline & & Worst & 14 & $10.1 \%$ \\
\hline & \multirow[t]{3}{*}{ Influence of restrictions on neonatal management } & No influence & 43 & $30.9 \%$ \\
\hline & & Negative influence & 85 & $61.2 \%$ \\
\hline & & Positive influence & 11 & $7.9 \%$ \\
\hline & \multirow[t]{2}{*}{ Breastfeeding during hospital stay } & Yes & 131 & $94.0 \%$ \\
\hline & & No & 8 & $6.0 \%$ \\
\hline & \multirow[t]{3}{*}{ Type of nutrition } & $\begin{array}{l}\text { Exclusive } \\
\text { breastfeeding }\end{array}$ & 98 & $70.5 \%$ \\
\hline & & Formula feeding & 38 & $27.3 \%$ \\
\hline & & Human donor milk & 3 & $2.2 \%$ \\
\hline & \multirow[t]{2}{*}{ Continued breastfeeding after discharge } & Yes & 132 & $95.0 \%$ \\
\hline & & No & 7 & $5.0 \%$ \\
\hline & \multirow[t]{2}{*}{ Still breastfeeding at the time of survey } & Yes & 126 & $90.6 \%$ \\
\hline & & No & 13 & $9.4 \%$ \\
\hline & \multirow[t]{3}{*}{ Influence of restrictions on breastfeeding } & No influence & 78 & $56.1 \%$ \\
\hline & & Negative influence & 51 & $36.7 \%$ \\
\hline & & Positive influence & 10 & $7.2 \%$ \\
\hline & \multirow{5}{*}{$\begin{array}{l}\text { Who supported you for breastfeeding after the discharge (more than one } \\
\text { choice available) }\end{array}$} & Midwife ${ }^{c}$ & 36 & $55.4 \%^{d}$ \\
\hline & & Partner & 27 & $41.5 \%^{d}$ \\
\hline & & Relative or friend & 18 & $27.7 \%^{d}$ \\
\hline & & Pediatrician & 4 & $6.1 \%^{d}$ \\
\hline & & No support & 74 & $53.2 \%$ \\
\hline
\end{tabular}

a Presence of missing data for these variables. Percentages were calculated on total of respondents: Afraid of receiving worst assistance for the pandemic $(N=$

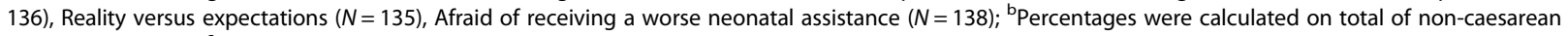
deliveries $(N=118) ;{ }^{c}$ This is the total of respondents declared any type of assistance in breastfeeding after discharge by midwife $(n=36)$. Among these, 20 new mothers claimed that they had assistance by a private midwife, another 20 by midwife of public surgery, and/or 5 by midwife of the hospital where they delivered. Total number is bigger than the frequency shown in Table $3(n=36)$ because this question allowed more than one choice. ${ }^{d}$ Percentages were calculated on the total of women who claimed to have received support for breastfeeding after the discharge $(N=65)$ 
Table 4 Changes in mental wellness and lifestyles during lockdown by socio-demographic characteristics, housing and living conditions

\begin{tabular}{|c|c|c|c|c|c|c|c|c|c|c|c|c|c|}
\hline \multirow{3}{*}{$\begin{array}{l} \\
\text { Age }\end{array}$} & \multirow[b]{3}{*}{ Less than 34} & \multicolumn{4}{|c|}{ Anxiety and depression } & \multicolumn{4}{|c|}{ Difficulties in healthy eating } & \multicolumn{4}{|c|}{ Reduction in physical exercise } \\
\hline & & \multicolumn{2}{|c|}{$\begin{array}{l}\text { PHQ-4 } \\
\text { Moderate } \\
\text { to Severe } \\
\mathrm{N}(\%)\end{array}$} & \multirow[t]{2}{*}{$\begin{array}{l}\text { Chi2 } p \text { - } \\
\text { value }\end{array}$} & \multirow{2}{*}{$\begin{array}{l}\text { PR }(95 \% \\
\text { Cl) }{ }^{a} \\
1\end{array}$} & \multicolumn{2}{|c|}{ Yes N (\%) } & \multirow[t]{2}{*}{$\begin{array}{l}\text { Chi2 } p \text { - } \\
\text { value }\end{array}$} & \multirow[t]{2}{*}{$\begin{array}{l}\text { PR }(95 \% \\
\text { Cl) }{ }^{\mathrm{a}}\end{array}$} & \multicolumn{2}{|c|}{ Yes N (\%) } & \multirow[t]{2}{*}{$\begin{array}{l}\text { Chi2 } p \text { - } \\
\text { value }\end{array}$} & \multirow{2}{*}{$\begin{array}{l}\text { PR (95\% } \\
\text { Cl) }{ }^{\text {a }} \\
1\end{array}$} \\
\hline & & 236 & $62.3 \%$ & & & 167 & $44.1 \%$ & & & 200 & $62.5 \%$ & & \\
\hline & From 35 & 141 & $63.8 \%$ & 0.71 & $\begin{array}{l}1.02(0.83- \\
1.26)\end{array}$ & 99 & $44.8 \%$ & 0.86 & $\begin{array}{l}1.01 \\
(0.79- \\
1.30)\end{array}$ & 111 & $60.7 \%$ & 0.68 & $\begin{array}{l}0.97 \\
(0.77- \\
1.22)\end{array}$ \\
\hline \multirow[t]{2}{*}{ Education } & $\begin{array}{l}\text { Less than } \\
\text { Bachelor }\end{array}$ & 158 & $68.7 \%$ & & 1 & 127 & $55.2 \%$ & & 1 & 112 & $63.3 \%$ & & 1 \\
\hline & $\begin{array}{l}\text { More than } \\
\text { Bachelor }\end{array}$ & 218 & $59.1 \%$ & 0.02 & $\begin{array}{l}0.86(0.70- \\
1.05)\end{array}$ & 138 & $37.4 \%$ & $<0.001$ & $\begin{array}{l}0.7(0.53- \\
0.86)\end{array}$ & 198 & $60.9 \%$ & 0.61 & $\begin{array}{l}0.96 \\
(0.76- \\
1.21)\end{array}$ \\
\hline \multirow[t]{2}{*}{$\begin{array}{l}\text { Satisfaction with } \\
\text { economical resources }\end{array}$} & $\begin{array}{l}\text { Not much } \\
\text { adeguate }\end{array}$ & 224 & $71.8 \%$ & & 1 & 153 & $49.0 \%$ & & 1 & 162 & $64.8 \%$ & & 1 \\
\hline & $\begin{array}{l}\text { Very } \\
\text { adeguate }\end{array}$ & 150 & $52.6 \%$ & $<0.001$ & $\begin{array}{l}0.73(0.60- \\
0.90)\end{array}$ & 113 & $39.6 \%$ & 0.02 & $\begin{array}{l}0.80 \\
(0.63- \\
1.03)\end{array}$ & 148 & $59.2 \%$ & 0.20 & $\begin{array}{l}0.91 \\
(0.73- \\
1.14)\end{array}$ \\
\hline \multirow{2}{*}{$\begin{array}{l}\text { Satisfaction with your } \\
\text { home }\end{array}$} & Not much & 172 & $74.4 \%$ & & 1 & 118 & $50.9 \%$ & & 1 & 128 & $65.5 \%$ & & 1 \\
\hline & Very much & 205 & $55.7 \%$ & $<0.001$ & $\begin{array}{l}0.75(0.61- \\
0.92)\end{array}$ & 148 & $40.2 \%$ & 0.01 & $\begin{array}{l}0.79 \\
(0.62- \\
1.01)\end{array}$ & 183 & $59.5 \%$ & 0.20 & $\begin{array}{l}0.92 \\
(0.73- \\
1.17)\end{array}$ \\
\hline \multirow[t]{2}{*}{ Partner supporting } & No & 78 & $77.2 \%$ & & 1 & 60 & $59.4 \%$ & & 1 & 52 & $66.7 \%$ & & 1 \\
\hline & Yes & 299 & $59.9 \%$ & 0.001 & $\begin{array}{l}0.77(0.60- \\
0.99)\end{array}$ & 206 & $41.3 \%$ & 0.001 & $\begin{array}{l}0.69 \\
(0.52- \\
0.93)\end{array}$ & 259 & $60.9 \%$ & 0.34 & $\begin{array}{l}0.91 \\
(0.68- \\
1.23)\end{array}$ \\
\hline \multirow{2}{*}{$\begin{array}{l}\text { Contacts with other } \\
\text { people }\end{array}$} & No & 239 & $63.0 \%$ & & 1 & 154 & $41.0 \%$ & & 1 & 197 & $62.1 \%$ & & 1 \\
\hline & Yes & 138 & $61.6 \%$ & 0.63 & $\begin{array}{l}0.96(0.78- \\
1.19)\end{array}$ & 112 & $50.0 \%$ & 0.03 & $\begin{array}{l}1.22 \\
(0.96- \\
1.56)\end{array}$ & 114 & $61.3 \%$ & 0.85 & $\begin{array}{l}0.98 \\
(0.78- \\
1.24)\end{array}$ \\
\hline \multirow[t]{3}{*}{ Availability of free time } & As before & 71 & $65.7 \%$ & & 1 & 45 & $41.7 \%$ & & 1 & 55 & $63.2 \%$ & & 1 \\
\hline & $\begin{array}{l}\text { Less than } \\
\text { before }\end{array}$ & 102 & $65.4 \%$ & & $\begin{array}{l}0.99(0.73- \\
1.34)\end{array}$ & 77 & $49.4 \%$ & & $\begin{array}{l}1.18 \\
(0.82- \\
1.74)\end{array}$ & 86 & $69.9 \%$ & & $\begin{array}{l}1.10 \\
(0.79- \\
1.55)\end{array}$ \\
\hline & $\begin{array}{l}\text { More than } \\
\text { before }\end{array}$ & 203 & $60.8 \%$ & 0.49 & $\begin{array}{l}0.92(0.70- \\
1.21)\end{array}$ & 143 & $42.8 \%$ & 0.33 & $\begin{array}{l}1.02 \\
(0.73- \\
1.44)\end{array}$ & 168 & $57.7 \%$ & 0.06 & $\begin{array}{l}0.91 \\
(0.67- \\
1.24)\end{array}$ \\
\hline \multirow[t]{2}{*}{ Other children at home } & No & 250 & $61.6 \%$ & & 1 & 165 & $40.6 \%$ & & 1 & 217 & $59.6 \%$ & & 1 \\
\hline & Yes & 127 & $65.5 \%$ & 0.35 & $\begin{array}{l}1.06(0.86- \\
1.31)\end{array}$ & 101 & $52.1 \%$ & 0.01 & $\begin{array}{l}1.28 \\
(1.00- \\
1.64)\end{array}$ & 94 & $67.6 \%$ & 0.10 & $\begin{array}{l}1.13 \\
(0.89- \\
1.44)\end{array}$ \\
\hline \multirow[t]{3}{*}{ Trimester of pregnancy } & First & 38 & $70.4 \%$ & & 1 & 16 & $29.6 \%$ & & 1 & 38 & $90.5 \%$ & & 1 \\
\hline & Second & 112 & $56.6 \%$ & & $\begin{array}{l}0.80(0.55- \\
1.16)\end{array}$ & 76 & $38.4 \%$ & & $\begin{array}{l}1.29 \\
(0.75- \\
2.22)\end{array}$ & 99 & $58.9 \%$ & & $\begin{array}{l}0.64 \\
(0.44- \\
0.93)\end{array}$ \\
\hline & Third & 223 & $64.8 \%$ & 0.07 & $\begin{array}{l}0.92(0.51- \\
1.30)\end{array}$ & 172 & $50.0 \%$ & 0.002 & $\begin{array}{l}1.69 \\
(1.01- \\
2.81)\end{array}$ & 172 & $59.9 \%$ & $<0.001$ & $\begin{array}{l}0.66 \\
(0.47- \\
0.94)\end{array}$ \\
\hline
\end{tabular}

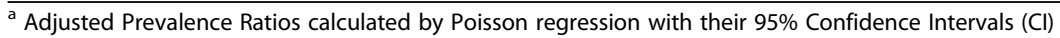

women, as demonstrated in previous studies [15]. On the other hand, it seems that staying at home facilitated the approach to healthy eating for the group with partner support and a higher socio-economic status. This results deserve further investigation and they could represent a starting point to develop new strategies for public health.

Most women hope for a labor and birth experience that enables them to use their physical and psychosocial 
capacities to labor and give birth to a healthy baby in a clinically, culturally, and psychologically safe environment with continuity of practical and emotional support from a birth companion, and with kind, sensitive clinical staff, who provide reassurance and technical competency. Among women who delivered during the pandemic, although three-fourths of the respondents declared to be afraid of giving birth during such a complex period, the overall experience was as expected or better than expected for $87 \%$ of the respondents. Despite more than half of the new mothers reported a negative influence on baby management and more than onethird of them reported a negative influence on their breastfeeding experience, the breastfeeding rate is consistent or even higher than before the pandemic [16], suggesting a slight discrepancy between expectations/ perceptions and actual facts, probably due to the anxiety and depression characteristics found in our sample. Exclusive breastfeeding rates in Italy ranged from 57 to $77 \%$ at discharge and 36 to $48 \%$ after 3 months [16], while $95 \%$ of our sample declared to perform it at discharge and $90.6 \%$ of them were still breastfeeding at the time of the survey. More than half of the new mothers received no support for breastfeeding after hospital discharge; however, almost all respondents continued to breastfeed their babies when discharged at home. It could be inferred that, in the impossibility to rely on external support, new mothers have empowered their internal resources with satisfying results.

The most accurate comparison we could make about the delivery and postpartum experience is with the Italian data of CeDAP published in 2016 by the Italian Ministry of Health. (http://www.salute.gov.it/imgs/C_17_ pubblicazioni_2881_allegato.pdf). The median age of women giving birth in Italy in 2016 was 33 years, consistent with our sample. Of women giving birth in 2016 in Italy, $27.8 \%$ were graduated, while in our sample the women with a bachelor were $61.8 \%$ in the pregnant group and $73.4 \%$ of the new mothers. In the report of 2016, it results that $55.3 \%$ of women giving birth was in-work, while in our sample 75.7 and $78.3 \%$ were inwork. This must be considered as a bias, as discussed later on. In 2016, the partner accompanied the woman during labor in $92.2 \%$ of cases, comparable to the rate of $92.4 \%$ in our sample. Furthermore, the cesarean section rate in our sample was just $15.1 \%$, much lower than the $33.7 \%$ in 2016 . However, we cannot speculate if this difference is given by the pandemic or it is just a selection bias.

The high level of anxiety and depression we found is consistent with other studies $[7,8]$. The prevalence in the first trimester is confirmed [8] while, differently from another study [7], in our survey this data was not correlated with age, primiparity, and living area. The correlation with economic difficulties and lower education is consistent with the literature [15], and some studies suggested that COVID-19 pandemic may even worsen social inequality [17].

Regarding the fact that a reduction of face-to-face visits could have occurred during the restrictions, a recent survey showed that patients are actually open to alternative models of prenatal care, including remote monitoring [18]. Future surveys could be done to determine if such changes would be judged positively. According to a Cochrane review [19], communicating the results of medical investigations by mobile phone messaging may make little or no difference to women's anxiety overall or in women with positive test results, but may reduce anxiety in women with negative test results. We cannot exclude that this method will be more largely implemented in future times, after the COVID-19 emergency and the lessons it gave us about face-to-face contact.

The high prevalence of anxiety and depressive symptoms in pregnant women and new mothers should be a public health issue, and screening for perinatal depression and anxiety should be considered during a pandemic. Under the circumstances of social distancing and isolation, psychological hotlines and online counseling would be a smart strategy to manage perinatal mental illness. The same strategy would be useful to help new mothers with baby management. Healthcare professionals should also ensure patients feel supported by continuing their routine prenatal care through telemedicine visits [20]. Clinicians might also consider recommending and encouraging "home" physical exercise, especially in women in the first trimester, who might be most worried about the sudden change of their lives.

Isolation, increased stress, and sedentary lifestyle in pregnancy can also lead to adverse pregnancy outcomes, such as preterm birth, gestational diabetes, and low birth weight [21, 22]. This survey represents a baseline questionnaire for those women who gave consent to be contacted, and they will be followed up as a cohort to identify possible complications. In a further part of our project, we are going to describe in greater detail how lockdown may influence neonatal outcomes.

The first limitation of the present study is related to nonrandom sampling: women are enrolled by newspaper advertisements, social media, and with the snowball method; the completeness check process was not exhaustive. This enrollment method accounts for the possible bias represented by the high number of respondents from Northern Italy, as the research group was based in Northern Italy and the spreading of the link to the survey by social media would have been greater and faster where the research was conceptualized. Moreover, 
the enrollment by social media and dedicated newspapers implies the intrinsic limit that the most wealthy and educated segments of the population might be more easily reached by the invitation to answer the survey, as suggested by the high rate of respondents with at least a bachelor's degree and reporting their income was highly sufficient to their needs. A second limitation is the lack of a validated questionnaire designed to capture such a delicate and unique moment. Third, depressive and anxiety symptoms were assessed using a short scale relying on self-reported measures and not providing a diagnosis. Finally, a potential bias may de that a propensity score analysis was not performed and we did not account for weighting of the items. Despite these limitations, this is the first study to assess some aspects of the lifestyle of pregnant women and new mothers during lockdown in Italy. Besides, the web-based method is a strength because it gave us the opportunity to interview a geographically dislocated population during a short time in the lockdown period.

Given the unicity of the SARS-CoV2 pandemic, we tried to give an overview of the experience of Italian pregnant women and new mothers during lockdown. Next steps will be to incorporate those findings in political choices. The WHO Executive Board recognizes the need to include women in decision making for outbreak preparedness and response, however there is still inadequate women representation in national and global COVID-19 policy spaces [23]. It is also important that health professionals commit themselves to help pregnant women and new mothers to overcome these difficult times.

\section{Conclusions}

In conclusion, we found a high prevalence of anxiety and depressive symptoms in pregnant women and new mothers, which should be a public health issue. Almost two-thirds of the respondents reported a reduction of physical activity during lockdown; therefore, clinicians might consider recommending and encouraging "home" physical exercise. On the other hand, about half of the sample improved their approach towards healthy eating and a very high breastfeeding rate was reported soon after birth: these data are an interesting starting point to develop new strategies for public health.

\section{Supplementary Information}

The online version contains supplementary material available at https://doi. org/10.1186/s12884-021-03904-4.

Additional file 1: Supplementary Material_questionnaire: survey_rev English version of the questionnaire

Additional file 2: Supplementary Material_questionnairelTA: survey_revITA: original Italian version of the questionnaire
Additional file 2: Supplementary Material questionnairelTA: survey_reviTA: original Italian version of the questionnaire

Acknowledgements

The authors would like to acknowledge Prof Mirela Kalcina and Dr Elena Osella for proofreading.

\section{Authors' contributions}

VS: conceptualization, methodology, software, data curation, writing original draft; AM: conceptualization, data curation, writing original draft; SC: formal analysis, review, and editing; GF: review and editing, visualization; MG: validation, review, and editing; ADP: project administration, review, and editing; RA: data curation, review, and editing; IR and DS: supervision, review, and editing. All authors read and approved the final version of the manuscript.

\section{Funding}

the research received no funding.

\section{Availability of data and materials}

The datasets generated and/or analysed during the current study are not publicly available due to privacy reasons but are available from the

corresponding author on reasonable request.

\section{Declarations}

\section{Ethics approval and consent to participate}

the consent to participate was required and the participation in the survey was voluntary and anonymous. Approval was obtained from the local Ethical Committee (Comitato Etico Interaziendale Novara CE 71/20), which

conformed to the principles embodied in the Declaration of Helsinki.

Consent for publication

Not applicable.

\section{Competing interests}

The authors declare that they have no competing interests.

\section{Author details}

${ }^{1}$ Obstetrics and Gynecology Unit, Department of Translational Medicine, University of Eastern Piedmont, Via Solaroli 17, 28100 Novara, Italy. ${ }^{2}$ Division of Pediatric, Department of Health Sciences, University of Eastern Piedmont, Novara, Italy. ${ }^{3}$ Obstetrics and Gynecology Unit, Maggiore della Carità Hospital, Novara, Italy. ${ }^{4}$ Department of Translational Medicine, University of Eastern Piedmont, Novara, Italy. ${ }^{5}$ CPO Piemonte, Turin, Italy.

Received: 28 July 2020 Accepted: 27 May 2021

Published online: 01 July 2021

References

1. Kraemer MUG, Yang C-H, Gutierrez B, Wu C-H, Klein B, Pigott DM, et al. The effect of human mobility and control measures on the COVID-19 epidemic in China. Science. 2020;368(6490):493-7.

2. Rasmussen SA, Smulian JC, Lednicky JA, Wen TS, Jamieson DJ. Coronavirus Disease 2019 (COVID-19) and pregnancy: what obstetricians need to know. Am J Obstet Gynecol. 2020;222(5):415-26.

3. Rasmussen SA, Jamieson DJ. Coronavirus Disease 2019 (COVID-19) and Pregnancy: Responding to a Rapidly Evolving Situation. Obstet Gynecol. 2020;135(5):999-1002.

4. Wenham C, Smith J, Morgan R. COVID-19: the gendered impacts of the outbreak. The Lancet. 2020;395(10227):846-8.

5. Della Gatta AN, Rizzo R, Pilu G, Simonazzi G. COVID19 during pregnancy: a systematic review of reported cases. Am J Obstet Gynecol. 2020; S0002937820304385.

6. Du L, Gu YB, Cui MQ, et al. [Investigation on demands for antenatal care services among 2002 pregnant women during the epidemic of COVID-19 in Shanghail. Zhonghua fu Chan ke za zhi. 2020;55(3):160-5.

7. Wu Y, Zhang C, Liu H, Duan C, Li C, Fan J, et al. Perinatal depressive and anxiety symptoms of pregnant women along with COVID-19 outbreak in China. Am J Obstet Gynecol. 2020;S0002937820305342. 
8. Saccone G, Florio A, Aiello F, Venturella R, De Angelis MC, Locci M, et al. Psychological Impact of COVID-19 in pregnant women. Am J Obstet Gynecol. 2020;50002937820305275.

9. Wang C, Pan R, Wan X, Tan Y, Xu L, Ho CS, et al. Immediate Psychological Responses and Associated Factors during the Initial Stage of the 2019 Coronavirus Disease (COVID-19) Epidemic among the General Population in China. Int J Environ Res Public Health. 2020;17(5):1729.

10. von Elm E, Altman DG, Egger M, Pocock SJ, Gøtzsche PC, Vandenbroucke JP. The Strengthening the Reporting of Observational Studies in Epidemiology (STROBE) Statement: Guidelines for reporting observational studies. Int J Surg. 2014;12(12):1495-9.

11. Eysenbach G. Improving the Quality of Web Surveys: The Checklist for Reporting Results of Internet E-Surveys (CHERRIES). J Med Internet Res. 2004; 6(3):e34.

12. Marcano Belisario JS, Jamsek J, Huckvale K, O'Donoghue J, Morrison CP, Car J. Comparison of self-administered survey questionnaire responses collected using mobile apps versus other methods. Cochrane Database Syst Rev. 2015;(7):MR000042.

13. Kroenke K, Spitzer RL, Williams JBW, Lowe B. An Ultra-Brief Screening Scale for Anxiety and Depression: The PHQ-4. Psychosomatics. 2009;50(6):613-21.

14. Physical activity and exercise during pregnancy and the postpartum period. ACOG Committee Opinion No. 804. American College of Obstetricians and Gynecologists. Obstet Gynecol. 2020;135:e178-88.

15. Lagadec N, Steinecker M, Kapassi A, Magnier AM, Chastang J, Robert S, et al, Factors influencing the quality of life of pregnant women: a systematic review. BMC Pregnancy Childbirth. 2018;18(1):455.

16. Davanzo R, Romagnoli C, Corsello G. Position Statement on Breastfeeding from the Italian Pediatric Societies. Ital J Pediatr. 2015;41(1):80.

17. Onwuzurike C, Meadows AR, Nour NM. Examining Inequities Associated With Changes in Obstetric and Gynecologic Care Delivery During the Coronavirus Disease 2019 (COVID-19) Pandemic. Obstet Gynecol. 2020; 136(1):37-41.

18. Peahl AF, Novara A, Heisler M, Dalton VK, Moniz MH, Smith RD. Patient Preferences for Prenatal and Postpartum Care Delivery: A Survey of Postpartum Women. Obstet Gynecol. 2020;135(5):1038-46.

19. Gurol-Urganci I, de Jongh T, Vodopivec-Jamsek V, Car J, Atun R. Mobile phone messaging for communicating results of medical investigations. Cochrane Database Syst Rev. 2012 Jun 13;2012(6):CD007456.

20. Jago CA, Singh SS, Moretti F. Coronavirus Disease 2019 (COVID-19) and Pregnancy: Combating Isolation to Improve Outcomes. Obstet Gynecol. 2020 Jul;136(1):33 - 6.

21. Elsenbruch S, Benson S, Rücke M, Rose M, Dudenhausen J, PincusKnackstedt MK, et al. Social support during pregnancy: effects on maternal depressive symptoms, smoking and pregnancy outcome. Hum Reprod. 2007;22(3):869-77.

22. Shapiro GD, Fraser WD, Frasch MG, Séguin JR. Psychosocial stress in pregnancy and preterm birth: associations and mechanisms. J Perinat Med. 2013 Nov:41(6):631-45.

23. Boniol M, Mclsaac M, Xu L, Wuliji T, Diallo K, et al. Gender equity in the health workforce: analysis of 104 countries. World Health Organization 2019. https://apps.who.int/iris/handle/10665/311314. License: CC BY-NC-SA $3.0 \mathrm{IGO}$

\section{Publisher's Note}

Springer Nature remains neutral with regard to jurisdictional claims in published maps and institutional affiliations.

Ready to submit your research? Choose BMC and benefit from:

- fast, convenient online submission

- thorough peer review by experienced researchers in your field

- rapid publication on acceptance

- support for research data, including large and complex data types

- gold Open Access which fosters wider collaboration and increased citations

- maximum visibility for your research: over $100 \mathrm{M}$ website views per year

At BMC, research is always in progress.

Learn more biomedcentral.com/submissions 